Check for updates

Cite this: J. Mater. Chem. C, 2020, 8, 7181

Received 1st March 2020,

Accepted 23rd April 2020

DOI: $10.1039 / \mathrm{d} 0 \mathrm{tc} 01053 \mathrm{~g}$

rsc.li/materials-c

\title{
2D layered perovskite containing functionalised benzothieno-benzothiophene molecules: formation, degradation, optical properties and photoconductivity $\dagger$
}

\author{
Wouter T. M. Van Gompel, (D) a Roald Herckens, (D) a Paul-Henry Denis, (D) ${ }^{a}$ \\ Martijn Mertens, (D) María C. Gélvez-Rueda, (D) ${ }^{b}$ Kristof Van Hecke, (D) ${ }^{c}$ \\ Bart Ruttens, ${ }^{d}$ Jan D'Haen, ${ }^{d}$ Ferdinand C. Grozema, (D) ${ }^{b}$ Laurence Lutsen ${ }^{\text {ad }}$ and \\ Dirk Vanderzande (iD *ad
}

\begin{abstract}
2D layered hybrid perovskites are currently in the spotlight for applications such as solar cells, lightemitting diodes, transistors and photodetectors. The structural freedom of 2D layered perovskites allows for the incorporation of organic cations that can potentially possess properties contributing to the performance of the hybrid as a whole. In this study, we incorporated a benzothieno[3,2- $b$ ] benzothiophene (BTBT) alkylammonium cation into the organic layer of a 2D layered lead iodide perovskite. The formation and degradation of this material are discussed in detail. It is shown that the use of a solvent vapour annealing method significantly enhances the absorption, emission and crystallinity of films of this 2D layered perovskite as compared to regular thermal annealing. The photoconductivity of the films was determined using time-resolved microwave conductivity (TRMC) as well as in a device. In both cases, the solvent vapour annealed films show markedly higher photoconductivity than the films obtained using the regular thermal annealing approach.
\end{abstract}

\section{Introduction}

Hybrid organic-inorganic perovskites are currently receiving a lot of attention, mainly due to the impressive increase in the power conversion efficiency of perovskite solar cells over the past decade. Next to the $3 \mathrm{D}$ hybrid perovskites, also lowerdimensional hybrid perovskites (2D, 1D and 0D) are starting to receive increased attention. This is generally related to their enhanced stability and extended structural and compositional

\footnotetext{
${ }^{a}$ Hybrid Materials Design (HyMaD), Institute for Materials Research (IMO-IMOMEC), Hasselt University, Martelarenlaan 42, B-3500 Hasselt, Belgium. E-mail: dirk.vanderzande@uhasselt.be

${ }^{b}$ Optoelectronic Materials Section, Department of Chemical Engineering, Delft University of Technology, Van der Maasweg 9, 2629 HZ Delft, The Netherlands ${ }^{c}$ XStruct, Department of Chemistry, Ghent University, Krijgslaan 281-S3, B-9000 Ghent, Belgium

${ }^{d}$ Associated Laboratory IMOMEC, Imec, Wetenschapspark 1, B-3590 Diepenbeek, Belgium

$\dagger$ Electronic supplementary information (ESI) available: Details on the synthesis of the BTBT cation, thin film deposition and annealing, synthesis and characterization of single-crystals and measurement techniques. Supporting figures include an absorption spectrum, XRD pattern, unit cell, SEM images, photoconductivity transients and $I-V$ curves. CCDC 1914880 and 1985268 . For ESI and crystallographic data in CIF or other electronic format see DOI: 10.1039/ dotc01053g
}

versatility compared to the $3 \mathrm{D}$ hybrids. ${ }^{1}$ The freedom in terms of the structure of the organic cations that can potentially be incorporated into the organic layer of $2 \mathrm{D}$ layered hybrid perovskites allows one to envision a functional organic layer which enhances the properties of the hybrid as a whole. ${ }^{1,2}$ The potential of incorporating functional organic molecules into 2 D layered hybrid perovskites is currently being realized. ${ }^{1-18}$ In this regard, oligothiophene derivatives have recently received a lot of attention as organic cations with tunable energy levels. ${ }^{12,13,16,18}$

We present here a $2 \mathrm{D}$ layered hybrid perovskite containing functionalised benzothieno[3,2- $b]$ benzothiophene (BTBT) molecules in the organic layer. BTBT and its derivatives have been used frequently in organic electronics, mainly because of their substantial charge carrier mobilities. ${ }^{19-22}$ The charge carrier mobility of a thin film of organic molecules is strongly affected by the degree of molecular ordering in this layer. The templating effect of the inorganic layer on the organic layer could result in long-range (i.e. single-crystal like) ordering of the organic molecules. ${ }^{23}$ Therefore, potentially higher charge carrier mobilities in the organic layer may be obtained than those achievable in purely organic thin films. ${ }^{23}$ The incorporation of BTBT molecules into the organic layer of a $2 \mathrm{D}$ layered perovskite was recently suggested in a computational study by Maheshwari et al. ${ }^{24}$ 
According to these calculations, the valence band maximum in such a 2D perovskite should be localized in the organic (BTBT) spacer layer, potentially bestowing "functional" properties to the organic layer. This motivated us to embark on an experimental study to incorporate such a BTBT derivative into a 2D layered perovskite.

In this study, a 2D layered hybrid perovskite containing monofunctionalised BTBT molecules is prepared. We explore the formation, degradation and optical properties of this hybrid. Difficulties in obtaining well-formed thin films of the 2D layered perovskite through regular thermal annealing procedures are discussed and we show that this issue can be overcome by employing a mixed thermal/solvent vapour annealing method instead. As exceedingly complex organic cations are explored, there is a need to develop convenient processing methods to obtain high-quality thin films of 2D perovskites containing such cations. Solvent vapour annealing ${ }^{25}$ has been used in the literature for methylammonium lead iodide, ${ }^{26-31}$ methylammonium lead bromide, ${ }^{32}$ (phenethyl-ammonium) ${ }_{2} \mathrm{PbI}_{4}{ }^{33}$ and multi-layered perovskites containing either propane-1,3-diammonium, butylammonium or phenethylammonium. ${ }^{34-36}$ This method is generally used to enhance the grain size and crystallinity of the thin films. ${ }^{25}$ We showcase the utility of this method for a 2D layered perovskite containing a complex BTBT derivative as an organic cation. We compared films obtained using a solvent vapour annealing method with those obtained using regular thermal annealing with photoconductivity time-resolved microwave conductivity measurements. We show that the maximum photoconductivity of the solvent vapour annealed films is significantly higher than that of the equivalent thermally annealed films.

\section{Results and discussion}

A mono-functionalised benzothienobenzothiophene (BTBT- $\mathrm{C}_{3}$ ) derivative with a propylammonium chain was synthesized (Fig. 1). Precursor solutions with a stoichiometry of $\mathrm{A}_{2} \mathrm{PbI}_{4}$ (with A being this derivative) were prepared.

When the spin-coated thin films are thermally annealed at different temperatures for $15 \mathrm{~min}$, the absorption spectra are virtually identical with a broad excitonic absorption peak located at $\sim 494 \mathrm{~nm}$ (Fig. 2). This excitonic peak position is characteristic for a 2D layered lead iodide perovskite. . $^{91,37-40}$

The corresponding XRD patterns of the thin films contain weak, equally spaced reflections with an interplanar spacing of $23 \AA$ A (Fig. 3).

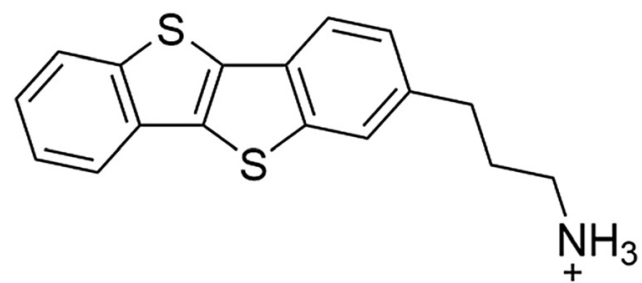

Fig. 1 Chemical structure of the benzothienobenzothiophene derivative (BTBT-C $\mathrm{C}_{3}$ ).

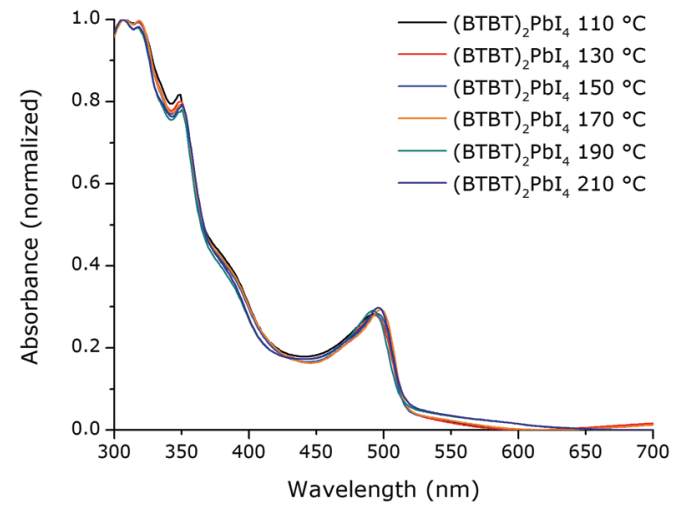

Fig. 2 Absorption spectra of films of (BTBT- $\left.\mathrm{C}_{3}\right)_{2} \mathrm{Pbl}_{4}$ annealed at different temperatures for $15 \mathrm{~min}$.

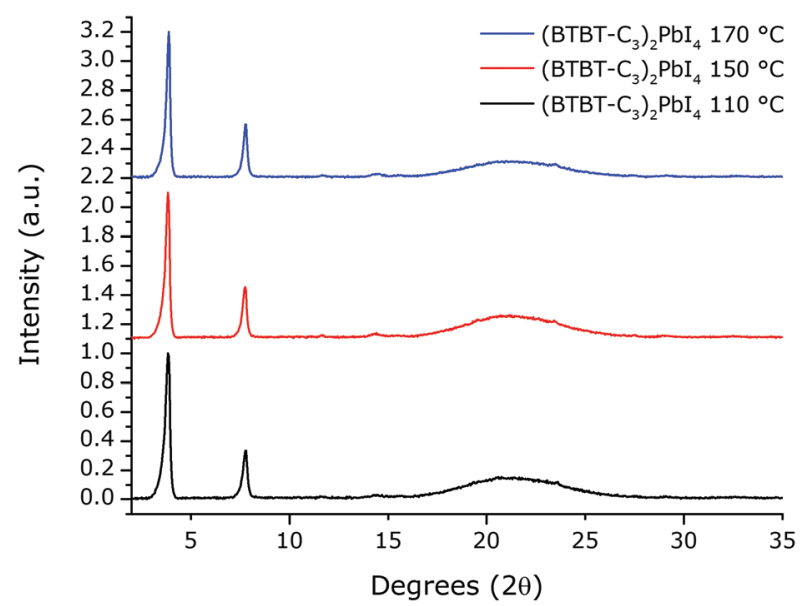

Fig. 3 XRD patterns of spin-coated films of $\left(B T B T-C_{3}\right)_{2} \mathrm{Pbl}_{4}$ thermally annealed for $15 \mathrm{~min}$ at different temperatures. The broad diffraction band between $\sim 15^{\circ}$ and $35^{\circ} 2 \theta$ is due to the quartz substrate.

These experiments indicate that a $2 \mathrm{D}$ perovskite phase was formed, however the films are weakly crystalline. In order to assess the formation (and degradation) of films of this material in more detail, in situ temperature-controlled absorption (T-UVVIS) and $\mathrm{X}$-ray diffraction measurements (T-XRD) were carried out.

\section{Phase formation and degradation}

T-UVVIS was carried out for (BTBT- $\left.\mathrm{C}_{3}\right)_{2} \mathrm{PbI}_{4}$ starting from a spin-coated film that was dried at $50{ }^{\circ} \mathrm{C}$ for $5 \mathrm{~min}$ on a hotplate immediately after spin-coating. A phase with a weak excitonic peak (at $\sim 494 \mathrm{~nm}$ ) is present until $\sim 140{ }^{\circ} \mathrm{C}$ (phase 1) after which a much more intense, slightly shifted, excitonic peak appears at $\sim 503 \mathrm{~nm}$ (phase 2) (Fig. 4). Starting at $\sim 160{ }^{\circ} \mathrm{C}$ this peak starts to disappear with formation of a phase with an excitonic peak at $\sim 424 \mathrm{~nm}$ (phase 3 ), which is expected to be a phase with an inorganic framework of a lower dimensionality based on the significant shift of the excitonic peak to higher energy $^{9}$ (Fig. 5). At higher temperatures, the whole system degrades into lead iodide. Note that the roughness of the film increases towards the end of the temperature program (the final degradation of the film), which leads to stronger 


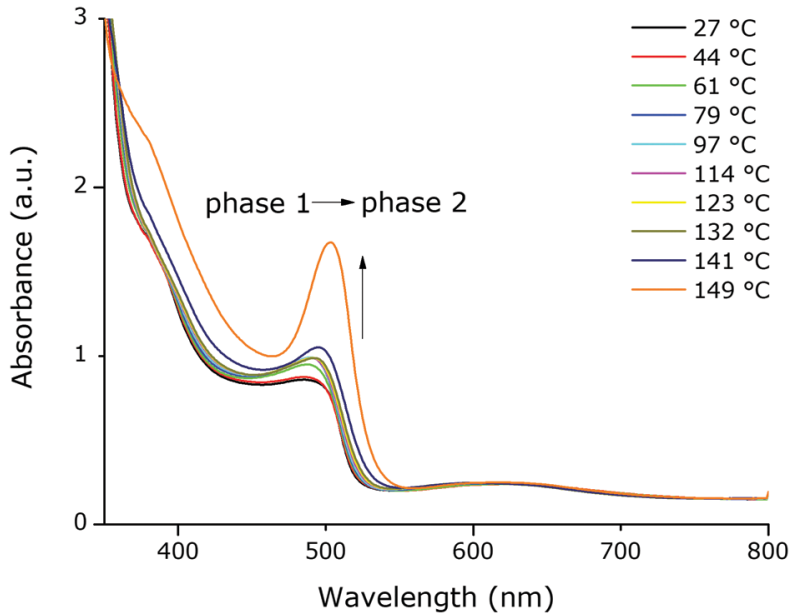

Fig. 4 Absorption spectra as a function of temperature, between $27^{\circ} \mathrm{C}$ and $150{ }^{\circ} \mathrm{C}$, starting from a spin-coated film of (BTBT- $\left.\mathrm{C}_{3}\right)_{2} \mathrm{Pbl}_{4}$ that was dried at $50{ }^{\circ} \mathrm{C}$ for $5 \mathrm{~min}$ before the in situ experiment. The black arrows indicate increasing absorbance as a function of temperature.

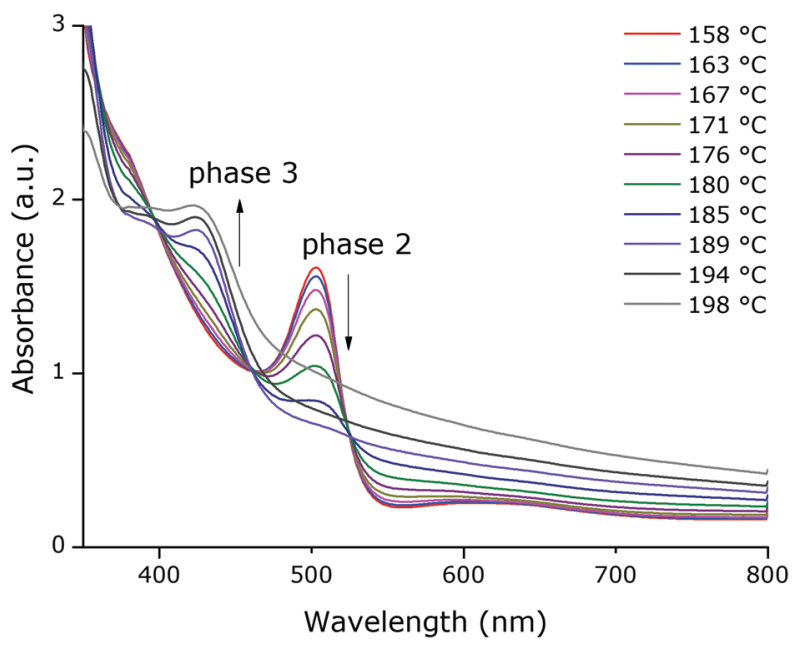

Fig. 5 Absorption spectra as a function of temperature, between $158{ }^{\circ} \mathrm{C}$ and $198{ }^{\circ} \mathrm{C}$, starting from a spin-coated film of (BTBT- $\left.\mathrm{C}_{3}\right)_{2} \mathrm{Pbl}_{4}$ that was dried at $50{ }^{\circ} \mathrm{C}$ for $5 \mathrm{~min}$ before the in situ experiment. The black arrows indicate decreasing or increasing absorbance as a function of temperature.

scattering and as a result an increase in the baseline of the absorption spectra. In Fig. 5, a clear isosbestic point located at $\sim 461 \mathrm{~nm}$ is present for the conversion of phase 2 into phase 3 , until temperatures at which the latter phase itself starts to thermally degrade. In Fig. 6 one can observe consecutively the formation of phase 2 (excitonic peak at $\sim 503 \mathrm{~nm}$ ) followed by the degradation of phase 2 into phase 3 (excitonic peak at $\sim 424 \mathrm{~nm}$ ) and finally degradation into lead iodide. This progressive degradation behaviour is confirmed by T-XRD experiments (vide infra).

T-XRD results are conform with the absorption spectra. At temperatures below $\sim 140{ }^{\circ} \mathrm{C}$, a weakly crystalline phase is present (phase 1). Then a highly crystalline phase is formed (phase 2). This phase is present until $\sim 180{ }^{\circ} \mathrm{C}$ in this experiment when reflections of phase 3 , corresponding to the

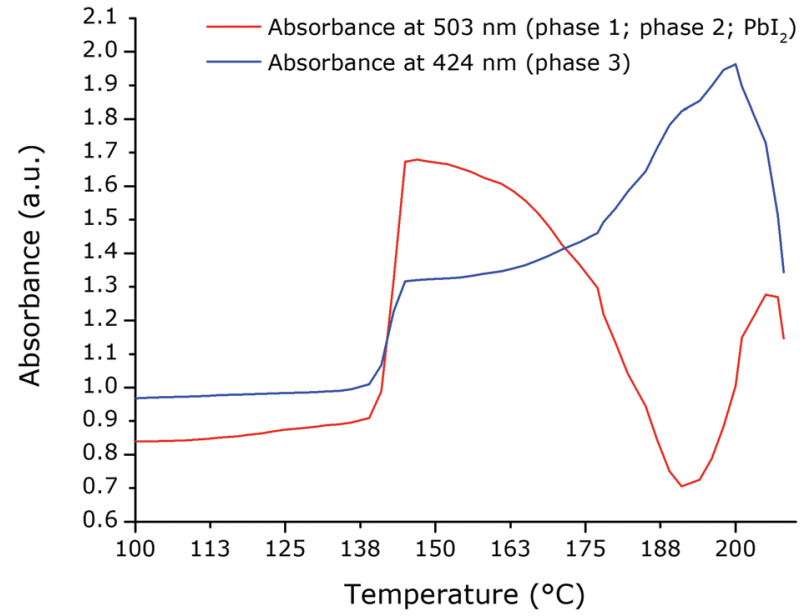

Fig. 6 Absorbance at $503 \mathrm{~nm}$ (red; following consecutively phase 1 , phase 2 and $\mathrm{Pbl}_{2}$ ) and at $424 \mathrm{~nm}$ (blue; following phase 3) as a function of temperature, extracted from the absorption spectra at different temperatures starting from a spin-coated film of $\left(B T B T-\mathrm{C}_{3}\right)_{2} \mathrm{Pbl}_{4}$ that was dried at $50{ }^{\circ} \mathrm{C}$ for $5 \mathrm{~min}$ before the in situ experiment. The increase in absorbance at $503 \mathrm{~nm}$ starting at $\sim 190{ }^{\circ} \mathrm{C}$ is due to the formation of lead iodide.

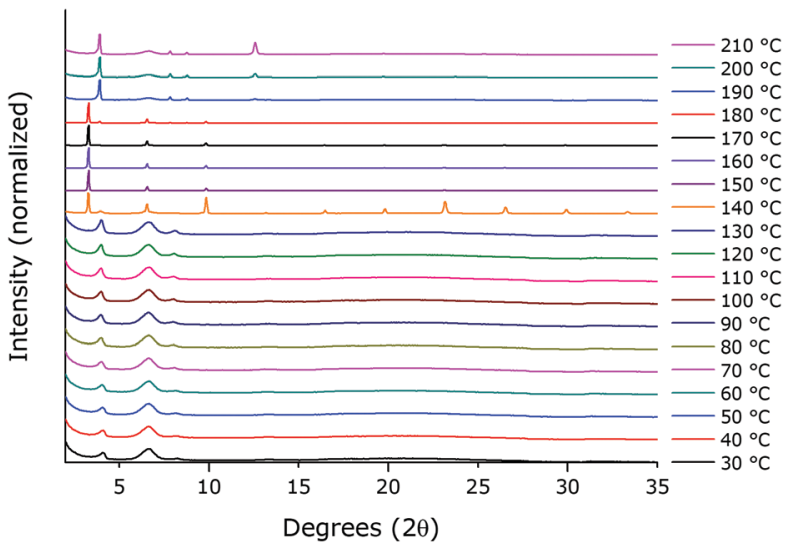

Fig. $7 \quad \mathrm{X}$-ray diffraction patterns (normalized) as a function of temperature starting from a spin-coated film of $\left(\mathrm{BTBT}-\mathrm{C}_{3}\right)_{2} \mathrm{Pbl}_{4}$ that was dried at $50{ }^{\circ} \mathrm{C}$ for $5 \mathrm{~min}$ before the in situ experiment. The broad peak at $\sim 6.6^{\circ} 2$. is due to Kapton from the temperature chamber of the XRD apparatus.

excitonic peak at $\sim 424 \mathrm{~nm}$ from T-UVVIS, start to appear, as well as lead iodide with a main reflection at $\sim 12.5^{\circ}$ (Fig. 7 ; the same plot with absolute intensities is shown in Fig. S4, ESI $\dagger$ ).

Single-crystals of phase 3 were obtained using an antisolvent vapour diffusion crystallization approach as detailed in the ESI $\dagger$ and their crystal structure was determined. The inorganic framework consists of a combination of face- and corner-sharing $\mathrm{PbI}_{6}{ }^{4-}$ octahedra (Fig. 8). The simulated XRD pattern for this crystal structure matches well with the experimental XRD pattern of a thin film of phase 3 (Fig. S5, ESI $\dagger$ ). This hybrid does indeed possess an inorganic framework of a lower dimensionality than that of a 2D layered perovskite, confirming what could be expected based on the higher energy excitonic peak position. 


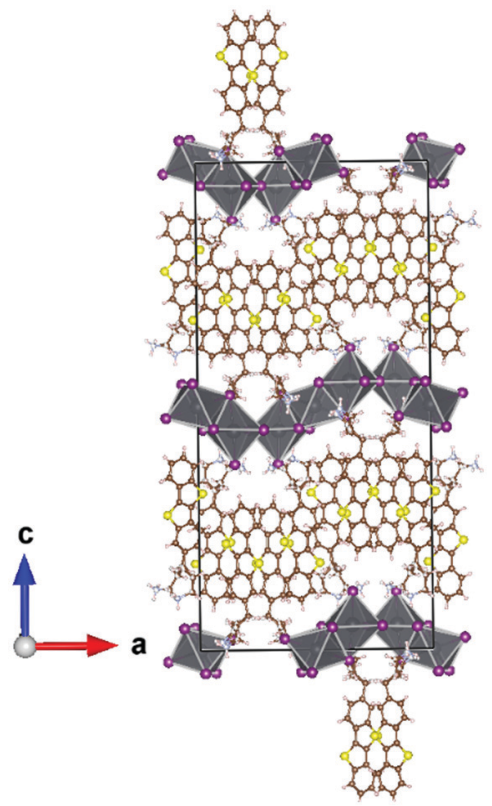

Fig. 8 Unit cell of $\left(\mathrm{BTBT}-\mathrm{C}_{3}\right)_{4} \mathrm{~Pb}_{3} \mathrm{l}_{10}$ (phase 3). The lead atoms are coloured bright grey, the iodine atoms dark purple, the nitrogen atoms light blue, the hydrogen atoms light pink, the carbon atoms dark orange and the sulphur atoms yellow. This figure was made using VESTA.

Regrettably, we were unable up until now to obtain singlecrystals of phase 2 (which we identify as the 2D layered perovskite phase based on excitonic peak position and the pattern of characteristic reflections in XRD) due to a strong tendency for crystals of phase 3 to form regardless of the supplied precursor stoichiometry. Next to the crystals of phase 3, crystals of a different hybrid containing gamma-butyrolactone (GBL) solvent molecules were obtained using an alternative crystal growth approach (as detailed in the ESI $\dagger$ ). These crystals have an empirical formula of $\left(\mathrm{BTBT}-\mathrm{C}_{3}\right) \mathrm{PbI}_{3} \cdot(\mathrm{GBL})$ and their inorganic framework consists of 1D ribbons of face-sharing octahedra (Fig. S6, ESI $\dagger$ ). Since we did not employ GBL to prepare precursor solutions for spin-coating, this crystal phase is not present in our thin films.

\section{Solvent vapour annealing}

Since obtaining highly crystalline films of this material using regular thermal annealing showed to be difficult, presumably due to the relatively high molecular weight and the rigidity of the BTBT cation, we were interested in testing a combined thermal-solvent vapour annealing method.

For this purpose, the high-boiling solvent DMSO (boiling point $=189{ }^{\circ} \mathrm{C}$ ) was used and the procedure was carried out inside of a glovebox. The method used was adapted from ref. 26. A drop of DMSO was put on a hot plate (kept at the annealing temperature of the film), the spin-coated film was quickly put on the hot-plate next to this drop and a Petri dish was used to immediately cover both the film and the drop. The DMSO drop evaporates and generates an atmosphere containing DMSO for the film during annealing. We hypothesize that the presence of DMSO vapour during the annealing of

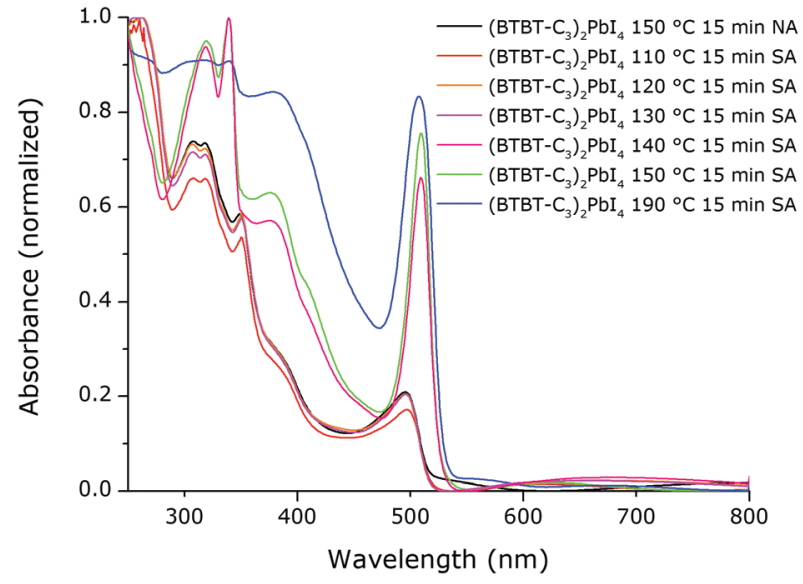

Fig. 9 Absorption spectra of films of $\left(B T B T-C_{3}\right)_{2} \mathrm{Pbl}_{4}$ that were solvent vapour annealed (SA) at different temperatures for $15 \mathrm{~min}$ compared to the thermally annealed sample (NA) at $150{ }^{\circ} \mathrm{C}$.

the films creates enhanced mobility for the different components, thereby facilitating the structure formation. Since the BTBT derivative that we use is relatively bulky and very rigid due to its fused ring system, we expect that this component is the main cause for the difficulty to obtain fully formed films of the perovskite using a short thermal annealing procedure. From a literature survey, it is clear that fully formed $2 \mathrm{D}$ perovskite films can be obtained using low annealing temperatures (or even without an annealing step) when small flexible organic cations such as butylammonium are employed, ${ }^{41}$ while much higher annealing temperatures are necessary when higher molecular weight organic cations such as quaterthiophene derivatives are used. ${ }^{15,42}$ This could be related to the difference in mobility (i.e. the energy needed to reorganize) between these different organic cations.

The resulting absorption spectra of solvent vapour annealed films are shown in Fig. 9, compared to the absorption spectrum of a film thermally annealed at $150{ }^{\circ} \mathrm{C}$ (denoted NA; from Fig. 2). Since all of the absorption spectra in Fig. 2 are all nearly identical, the one for the film annealed at $150{ }^{\circ} \mathrm{C}$ was chosen here as a reference. As can be seen, for solvent vapour annealing (denoted SA) at $140{ }^{\circ} \mathrm{C}, 150{ }^{\circ} \mathrm{C}$ and $190{ }^{\circ} \mathrm{C}$ for $15 \mathrm{~min}$, intense excitonic absorption peaks are obtained. Note that a certain threshold annealing temperature is still required for solvent vapour annealing since the samples annealed at temperatures below $140{ }^{\circ} \mathrm{C}$ for 15 min do not possess an intense excitonic absorption peak. Notice also that in the absorption spectra with the strong excitonic peaks $\left(>140{ }^{\circ} \mathrm{C}\right)$, the shape of the absorption spectrum clearly changes around $315 \mathrm{~nm}$. This region corresponds to the absorption of BTBT molecules (Fig. S7, ESI $\dagger$ ). It is known in literature that the peaks in the absorption spectrum of BTBT organic small molecules shift and change in this wavelength region depending on the type of aggregation. ${ }^{43}$ Therefore, we hypothesize that this change in spectral shape could be an indication for a difference in the stacking (or the extent of ordering) of the BTBT molecules inside of the hybrid. For the film that was solvent vapour 


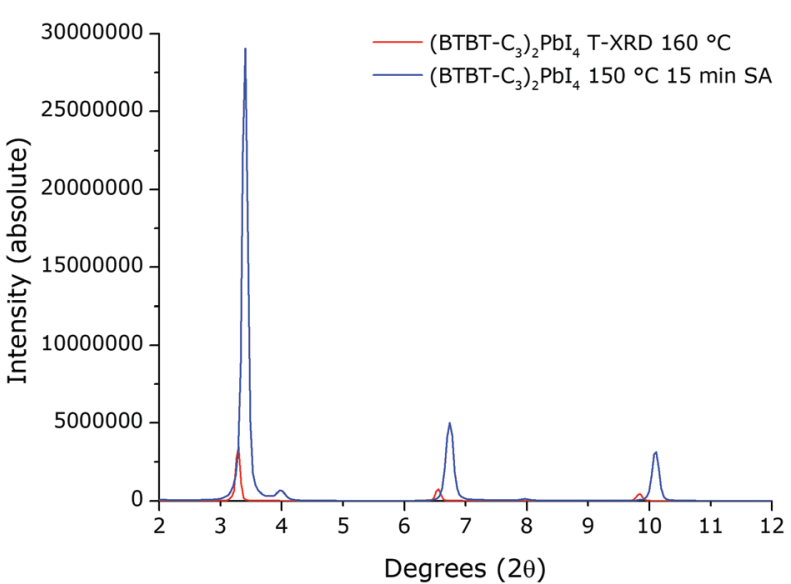

Fig. 10 Comparison between the XRD patterns of (BTBT- $\left.\mathrm{C}_{3}\right)_{2} \mathrm{Pbl}_{4}$ films subjected to different treatments. The blue pattern belongs to a film that was solvent vapour annealed (SA) at $150^{\circ} \mathrm{C}$ for $15 \mathrm{~min}$ and the red pattern belongs to a film from T-XRD at $160{ }^{\circ} \mathrm{C}$ (from Fig. 9).

annealed at $190{ }^{\circ} \mathrm{C}$, the shape in this region is different again. This could be related to the presence of more substantial amounts of phase 3 present in this film due to the degradation of the 2D hybrid (Fig. S8, ESI $\dagger$ ).

The XRD pattern of the film that was solvent vapour annealed at $150{ }^{\circ} \mathrm{C}$ for $15 \mathrm{~min}$ (Fig. 10) has very intense reflections, even relative to a pattern obtained from T-XRD where the total annealing time for the film is much longer (see ESI $\dagger$ for details on the T-XRD experiment). Note that all of our samples were prepared using spin-coating with the same spin settings and starting from a precursor solution with the same concentration. This suggests that the degree of crystallinity and/or the degree of orientation for this solvent annealed film is much higher than for the other samples. Note that there are reflections present in the pattern corresponding to phase 3 identified above using T-XRD and T-UVVIS. For the film that was thermally annealed at $150{ }^{\circ} \mathrm{C}$ for 15 minutes without solvent vapour annealing (from Fig. 3), the full width at half maximum (FWHM) of the first and second reflections in the pattern (respectively $0.26^{\circ}$ and $0.25^{\circ}$ ) is significantly higher than for the first and second reflections (respectively $0.11^{\circ}$ and $0.13^{\circ}$ ) in the pattern of the film that was solvent vapour annealed at $150{ }^{\circ} \mathrm{C}$ for $15 \mathrm{~min}$ (from Fig. 10). The FWHM for the reflections in the patterns for the other thermally annealed films are also significantly higher than for the equivalent solvent vapour annealed films. Combined with the significantly enhanced reflection intensity, the decrease in the FWHM of the reflections suggests the growth of a larger density of coherently scattering crystalline domains in the solvent vapour annealed films, resulting in enhanced overall crystallinity. ${ }^{44}$

As could be expected based on the absorption spectra and the XRD patterns, this solvent annealed film also possesses relatively strong excitonic emission (Fig. 11). Consistent with the absorption spectra (Fig. 9), the emission intensity of the films that were solvent annealed at $150{ }^{\circ} \mathrm{C}$ and $190{ }^{\circ} \mathrm{C}$ (giving rise to intense excitonic absorption peaks) is orders of magnitude higher than that of the film solvent annealed at $110{ }^{\circ} \mathrm{C}$

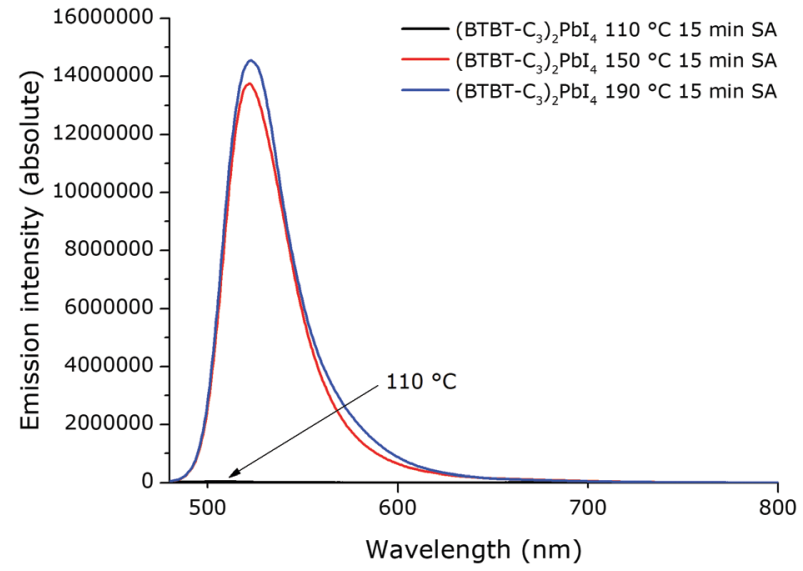

Fig. 11 Emission spectra of films of $\left(B T B T-C_{3}\right)_{2} \mathrm{Pbl}_{4}$ that were solvent annealed for $15 \mathrm{~min}$ at different temperatures. The films were excited at $430 \mathrm{~nm}$.

(not possessing the strong excitonic absorption peak). Likewise, the emission intensity for films obtained using regular thermal annealing, for the same annealing time, is orders of magnitude lower than for the film that was solvent annealed at $150{ }^{\circ} \mathrm{C}$ (Fig. S9-S11, ESI $\dagger$ ). Moreover, in the emission spectra of the thermally annealed films, there is an additional weak emission feature at lower energies (higher wavelengths) than the exitonic emission peak. This could be related to the emission from defects present in these films ${ }^{45}$ which would be consistent with the hypothesis that the $2 \mathrm{D}$ perovskite in these thermally annealed films is not fully formed. From SEM images, there is no significant difference in film morphology between films that were annealed using the regular thermal annealing and films that were solvent vapour annealed (Fig. S12, ESI $\dagger$ ).

\section{Photoconductivity TRMC}

In order to determine if the superior absorption characteristics and enhanced crystallinity of the films obtained using solvent vapour annealing translate into superior electronic transport properties, we measured the photoconductivity time-resolved microwave conductivity (TRMC) of solvent vapour-annealed films as well as of thermally annealed films. The photoconductivity TRMC measurements determine the product of the sum of mobility of charge carriers $\left(\sum \mu\right)$ and yield of dissociation of charge carriers $(\varphi)$ in semiconductor materials according to eqn (1). ${ }^{46}$ The yield of dissociation $(\varphi)$ strongly depends on the exciton binding energy of the material studied. It is possible that photogenerated charge carriers (excitons) recombine during the pulse without contributing to the photoconductivity signal (response time of the microwave setup is $\sim 18 \mathrm{~ns}$ ).

$$
\varphi \sum \mu=\frac{\Delta G_{\max }}{I_{0} \beta e F_{\mathrm{A}}}
$$

Here, $\Delta G_{\max }$ is the maximum photoconductance, $I_{0}$ is the number of photons per unit area per pulse, $\beta$ is defined by the dimensions of the microwave cavity, $e$ is the elementary charge, and $F_{\mathrm{A}}$ is the fraction of photons that is absorbed by the sample. The maximum photoconductance gives an indication 


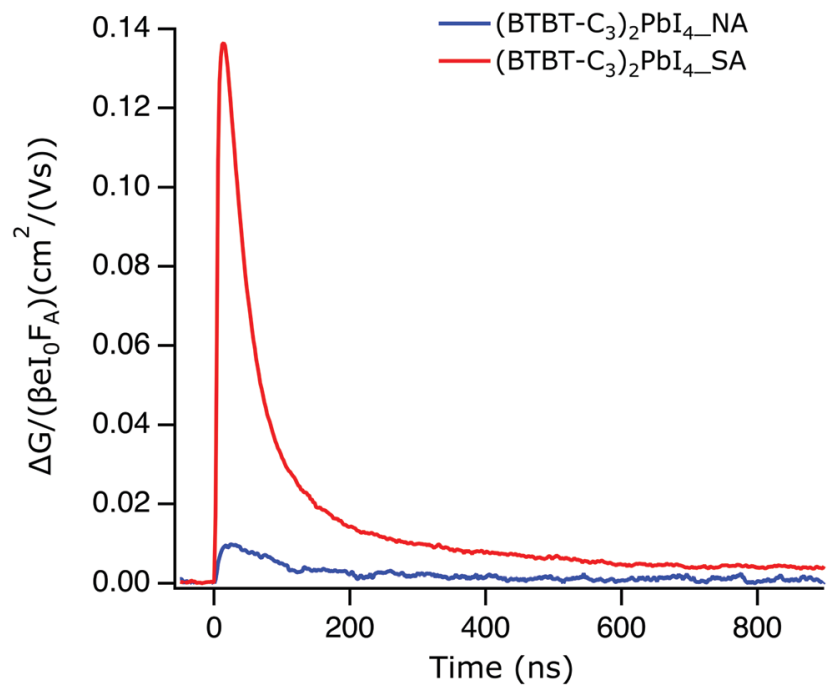

Fig. 12 Photoconductivity TRMC of (BTBT-C3) ${ }_{2} \mathrm{Pbl}_{4}$ thermal evaporated films (NA) and solvent vapour annealed films (SA). The films were excited at $\sim 490 \mathrm{~nm}$ with a photon intensity of $4.3 \times 10^{12} \mathrm{ph} \mathrm{cm}^{-2}$ (concentration of $\sim 1014 \mathrm{~cm}^{-3}$ ).

of the maximum photoconductivity $\left(\varphi \sum \mu\right)$ of the material as after the pulse, the photoconductivity decreases in time due to charge recombination or trapping. ${ }^{46}$ As mentioned, the yield of dissociation is intrinsic to the exciton binding energy of the material. However, the mobility of charge carriers is locally probed by the microwave field. As a result, the mobility depends on the crystallinity (grain size and defects) of the sample. From Fig. 12, it is clear that the photoconductivity of solvent vapour-annealed films is one order of magnitude larger than of thermally annealed films. The photoconductivity of solvent vapour-annealed films, $\sim 0.2 \mathrm{~cm}^{2} \mathrm{~V}^{-1} \mathrm{~s}^{-1}$, is comparable to values obtained for $2 \mathrm{D}$ perovskites with the same technique (Fig. S13, ESI $\dagger$ ). ${ }^{11,47}$ As the exciton binding energy is expected to be similar for both films, hence the yield of dissociation, the larger photoconductivity is due to a larger mobility of charge carriers in the solvent vapour-annealed films, likely caused by the improved crystallinity.

\section{Device characteristics}

We wanted to verify if the higher photoconductivity of the solvent vapour annealed films measured using TRMC also results in superior device characteristics. Devices with a simple architecture were made, consisting of films deposited directly onto a quartz substrate with a gold electrode evaporated directly on top of the films. A mask was used for the deposition of the gold electrode such that interdigitating finger structures are obtained (Fig. S14, ESI $\dagger$ ). In this way, a current is measured between these interdigitating fingers when a voltage is applied over them. Note that it is not the purpose of this preliminary study to obtain highly optimized optoelectronic devices. However, equivalent devices were prepared in duplicate using either regularly thermally annealed or solvent vapour annealed films. The devices were subjected to a light intensity of 1 sun with a spectrum of A.M. 1.5G (ASTM). The result is shown

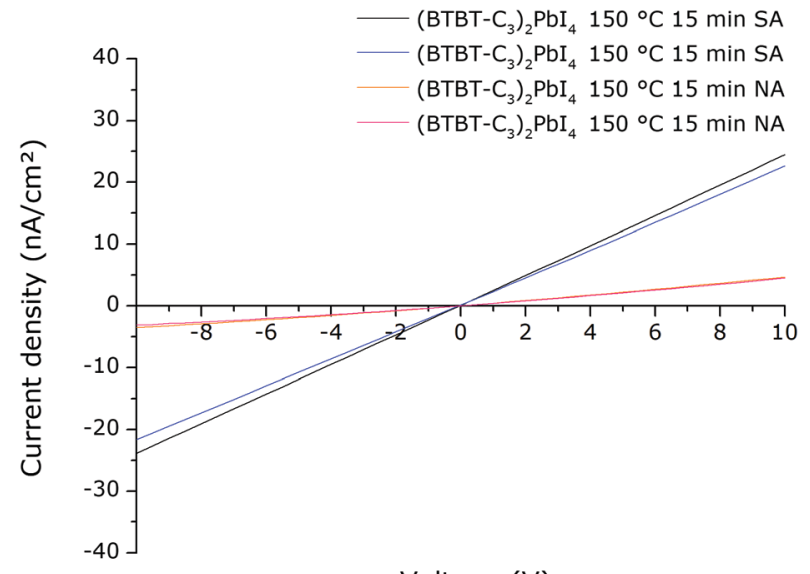

Voltage (V)

Fig. 13 Current density-voltage $(J-V)$ characteristics for four (BTBT$\left.\mathrm{C}_{3}\right)_{2} \mathrm{Pbl}_{4}$ devices, two of which contain a film that was not solvent vapour annealed (NA) and two of which contain a film that was solvent annealed (SA).

in Fig. 13 (in all cases for the cell with the largest spacing between the finger structures). It is clear that the light current density extracted at a certain applied voltage is significantly higher for the solvent vapour annealed films compared to the regular thermally annealed films. This indicates that the superior film characteristics do indeed result in enhanced optoelectronic characteristics, in this case, extracted light current density under applied voltage. The dark current density of the films was also measured. Compared to the dark current density, the light current density is a factor of $\sim 200-1000$ higher (depending on the applied voltage between $-10 \mathrm{~V}$ and $+10 \mathrm{~V}$ ) (Fig. S15 and S16, ESI $\dagger$ ). The dark current density for the devices containing the solvent vapour annealed films is similar to that of devices containing the regularly annealed films (Fig. S17, ESI†).

In conclusion, the solvent vapour annealing method can significantly reduce the annealing temperature needed to obtain (BTBT- $\left.\mathrm{C}_{3}\right)_{2} \mathrm{PbI}_{4}$ films with enhanced absorption, emission, crystallinity, photoconductivity and light current density under an applied voltage.

\section{Conclusions}

A benzothieno[3,2- $b]$ benzothiophene (BTBT) alkylammonium cation was incorporated into the organic layer of a $2 \mathrm{D}$ layered lead iodide perovskite. We show that the $2 \mathrm{D}$ layered hybrid degrades into a hybrid with an inorganic network of a lower dimensionality consisting of face- and corner-sharing $\mathrm{PbI}_{6}{ }^{4-}$ octahedra before further degradation of the material system into lead iodide. Using a mixed thermal/solvent vapour annealing approach, films of the 2D layered perovskite with enhanced absorption, emission and crystallinity were obtained. These solvent annealed films also possess enhanced photoconductivity in time-resolved microwave conductivity measurements and devices. Future work will be focussed on exploring the device physics of BTBT 2D layered perovskite-based optimized optoelectronic devices in detail. Furthermore, a computational study 
into the electronic structure of the $2 \mathrm{D}$ layered perovskite is foreseen when single crystals of this phase are obtained that allow determining its crystal structure.

\section{Conflicts of interest}

There are no conflicts to declare.

\section{Acknowledgements}

W. T. M. V. G., L. L. and D. V. acknowledge the FWO for the funding of the SBO project PROCEED (FWO-S002019N) and the senior FWO research project G043320N. M. M. is an SB PhD fellow at FWO (Number $1 \mathrm{~S} 20118 \mathrm{~N}$ ), R. H. is a PhD in chemistry currently employed as an R\&D Project Leader at Agfa and P.-H. D. is a special research fund (BOF) doctoral (PhD) student at UHasselt/IMO. The research leading to these results in the Delft University of Technology has received funding from the European Research Council Horizon 2020 ERC Grant Agreement no. 648433. KVH thanks the Hercules Foundation (AUGE/11/029) and the Special Research Fund (BOF) - UGent (01N03217) for funding.

\section{References}

1 L. Mao, C. C. Stoumpos and M. G. Kanatzidis, J. Am. Chem. Soc., 2019, 141, 1171-1190.

2 G. Grancini and M. K. Nazeeruddin, Nat. Rev. Mater., 2018, 4, 4-22.

3 H. Tsai, R. Asadpour, J. C. Blancon, C. C. Stoumpos, J. Even, P. M. Ajayan, M. G. Kanatzidis, M. A. Alam, A. D. Mohite and W. Nie, Nat. Commun., 2018, 9, 2130.

4 W. T. M. Van Gompel, R. Herckens, K. Van Hecke, B. Ruttens, J. D'Haen, L. Lutsen and D. Vanderzande, Chem. Commun., 2019, 55, 2481-2484.

5 H. Hu, F. Meier, D. Zhao, Y. Abe, Y. Gao, B. Chen, T. Salim, E. E. M. Chia, X. Qiao, C. Deibel and Y. M. Lam, Adv. Mater., 2018, 30, 1707621.

6 M. D. Smith, B. A. Connor and H. I. Karunadasa, Chem. Rev., 2019, 119, 3104-3139.

7 J. V. Passarelli, D. J. Fairfield, N. A. Sather, M. P. Hendricks, H. Sai, C. L. Stern and S. I. Stupp, J. Am. Chem. Soc., 2018, 140, 7313-7323.

8 M. C. Gelvez-Rueda, W. T. M. Van Gompel, R. Herckens, L. Lutsen, D. Vanderzande and F. C. Grozema, J. Phys. Chem. Lett., 2020, 11, 824-830.

9 W. T. M. Van Gompel, R. Herckens, K. Van Hecke, B. Ruttens, J. D'Haen, L. Lutsen and D. Vanderzande, ChemNanoMat, 2019, 5, 323-327.

10 N. Marchal, W. Van Gompel, M. C. Gelvez-Rueda, K. Vandewal, K. Van Hecke, H. G. Boyen, B. Conings, R. Herckens, S. Maheshwar, L. Lutsen, C. Quarti, F. C. Grozema, D. Vanderzande and D. Beljonne, Chem. Mater., 2019, 31, 6880-6888.
11 R. Herckens, W. T. M. Van Gompel, W. Y. Song, M. C. Gelvez-Rueda, A. Maufort, B. Ruttens, J. D'Haen, F. C. Grozema, T. Aernouts, L. Lutsen and D. Vanderzande, J. Mater. Chem. A, 2018, 6, 22899-22908.

12 W. A. Dunlap-Shohl, E. T. Barraza, A. Barrette, S. Dovletgeldi, G. Findik, D. J. Dirkes, C. Liu, M. K. Jana, V. Blum, W. You, K. Gundogdu, A. D. Stiff-Roberts and D. B. Mitzi, Mater. Horiz., 2019, 6, 1707-1716.

13 C. Liu, W. Huhn, K. Z. Du, A. Vazquez-Mayagoitia, D. Dirkes, W. You, Y. Kanai, D. B. Mitzi and V. Blum, Phys. Rev. Lett., 2018, 121, 146401.

14 J. Leveillee, C. Katan, J. Even, D. Ghosh, W. Nie, A. D. Mohite, S. Tretiak, A. Schleife and A. J. Neukirch, Nano Lett., 2019, 19, 8732-8740.

15 Y. Gao, Z. Wei, P. Yoo, E. Shi, M. Zeller, C. Zhu, P. Liao and L. Dou, J. Am. Chem. Soc., 2019, 141, 15577-15585.

16 Y. Gao, E. Shi, S. Deng, S. B. Shiring, J. M. Snaider, C. Liang, B. Yuan, R. Song, S. M. Janke, A. Liebman-Pelaez, P. Yoo, M. Zeller, B. W. Boudouris, P. Liao, C. Zhu, V. Blum, Y. Yu, B. M. Savoie, L. Huang and L. Dou, Nat. Chem., 2019, 11, 1151-1157.

17 Z. Fang, M. Shang, Y. Zheng, T. Zhang, Z. Du, G. Wang, X. Duan, K.-C. Chou, C.-H. Lin, W. Yang, X. Hou and T. Wu, Mater. Horiz., 2020, 7, 1042-1050.

18 S. Deng, J. M. Snaider, Y. Gao, E. Shi, L. Jin, R. D. Schaller, L. Dou and L. Huang, J. Chem. Phys., 2020, 152, 044711.

19 C. Niebel, Y. Kim, C. Ruzié, J. Karpinska, B. Chattopadhyay, G. Schweicher, A. Richard, V. Lemaur, Y. Olivier, J. Cornil, A. R. Kennedy, Y. Diao, W.-Y. Lee, S. Mannsfeld, Z. Bao and Y. H. Geerts, J. Mater. Chem. C, 2015, 3, 674-685.

20 K. Takimiya, I. Osaka, T. Mori and M. Nakano, Acc. Chem. Res., 2014, 47, 1493-1502.

21 Y. Tsutsui, G. Schweicher, B. Chattopadhyay, T. Sakurai, J. B. Arlin, C. Ruzie, A. Aliev, A. Ciesielski, S. Colella, A. R. Kennedy, V. Lemaur, Y. Olivier, R. Hadji, L. Sanguinet, F. Castet, S. Osella, D. Dudenko, D. Beljonne, J. Cornil, P. Samori, S. Seki and Y. H. Geerts, Adv. Mater., 2016, 28, 7106-7114.

22 R. Janneck, N. Pilet, S. P. Bommanaboyena, B. Watts, P. Heremans, J. Genoe and C. Rolin, Adv. Mater., 2017, 29, 1703864.

23 D. B. Mitzi, J. Chem. Soc., Dalton Trans., 2001, 1-12.

24 S. Maheshwari, T. J. Savenije, N. Renaud and F. C. Grozema, J. Phys. Chem. C, 2018, 122, 17118-17122.

25 W. A. Dunlap-Shohl, Y. Zhou, N. P. Padture and D. B. Mitzi, Chem. Rev., 2019, 119, 3193-3295.

26 Z. Xiao, Q. Dong, C. Bi, Y. Shao, Y. Yuan and J. Huang, Adv. Mater., 2014, 26, 6503-6509.

27 Y. Deng, E. Peng, Y. Shao, Z. Xiao, Q. Dong and J. Huang, Energy Environ. Sci., 2015, 8, 1544-1550.

28 Q. Liang, J. Liu, Z. Cheng, Y. Li, L. Chen, R. Zhang, J. Zhang and Y. Han, J. Mater. Chem. A, 2016, 4, 223-232.

29 L. Hu, G. Shao, T. Jiang, D. Li, X. Lv, H. Wang, X. Liu, H. Song, J. Tang and H. Liu, ACS Appl. Mater. Interfaces, 2015, 7, 25113-25120.

30 H. Yu, X. D. Liu, Y. J. Xia, Q. Q. Dong, K. C. Zhang, Z. W. Wang, Y. Zhou, B. Song and Y. F. Li, J. Mater. Chem. A, 2016, 4, 321-326. 
31 J. R. Lian, Q. Wang, Y. B. Yuan, Y. C. Shao and J. S. Huang, J. Mater. Chem. A, 2015, 3, 9146-9151.

32 S. H. Chin, J. W. Choi, H. C. Woo, J. H. Kim, H. S. Lee and C. L. Lee, Nanoscale, 2019, 11, 5861-5867.

33 D. Liang, Y. Peng, Y. Fu, M. J. Shearer, J. Zhang, J. Zhai, Y. Zhang, R. J. Hamers, T. L. Andrew and S. Jin, ACS Nano, 2016, 10, 6897-6904.

34 C. Ma, D. Shen, T. W. Ng, M. F. Lo and C. S. Lee, Adv. Mater., 2018, 30, 1800710.

35 J. Qing, X. K. Liu, M. J. Li, F. Liu, Z. C. Yuan, E. Tiukalova, Z. B. Yan, M. Duchamp, S. Chen, Y. M. Wang, S. Bai, J. M. Liu, H. J. Snaith, C. S. Lee, T. C. Sum and F. Gao, Adv. Energy Mater., 2018, 8, 1800185.

36 Z. H. Zheng, H. B. Lan, Z. H. Su, H. X. Peng, J. T. Luo, G. X. Liang and P. Fan, Sci. Rep., 2019, 9, 17422.

37 G. C. Papavassiliou and I. B. Koutselas, Synth. Met., 1995, 71, 1713-1714.

38 G. C. Papavassiliou, G. A. Mousdis and I. B. Koutselas, $A d v$. Mater. Opt. Electron., 1999, 9, 265-271.

39 K. Pradeesh, K. N. Rao and G. V. Prakash, J. Appl. Phys., 2013, 113, 083523.
40 K. Z. Du, Q. Tu, X. Zhang, Q. Han, J. Liu, S. Zauscher and D. B. Mitzi, Inorg. Chem., 2017, 56, 9291-9302.

41 D. H. Cao, C. C. Stoumpos, O. K. Farha, J. T. Hupp and M. G. Kanatzidis, J. Am. Chem. Soc., 2015, 137, 7843-7850.

42 D. B. Mitzi, K. Chondroudis and C. R. Kagan, Inorg. Chem., 1999, 38, 6246-6256.

43 V. S. Vyas, R. Gutzler, J. Nuss, K. Kern and B. V. Lotsch, CrystEngComm, 2014, 16, 7389-7392.

44 C. M. M. Soe, W. Y. Nie, C. C. Stoumpos, H. Tsai, J. C. Blancon, F. Z. Liu, J. Even, T. J. Marks, A. D. Mohite and M. G. Kanatzidis, Adv. Energy Mater., 2018, 8, 1700979.

45 G. Zhou, B. Su, J. Huang, Q. Zhang and Z. Xia, Mater. Sci. Eng., $R$, 2020, 141, 100548.

46 T. J. Savenije, A. J. Ferguson, N. Kopidakis and G. Rumbles, J. Phys. Chem. C, 2013, 117, 24085-24103.

47 M. C. Gelvez-Rueda, E. M. Hutter, D. H. Cao, N. Renaud, C. C. Stoumpos, J. T. Hupp, T. J. Savenije, M. G. Kanatzidis and F. C. Grozema, J. Phys. Chem. C, 2017, 121, 26566-26574. 